\title{
1. PRODUCING A GEOMETRICAL DRAWING
}

Before attempting to produce a drawing of high quality one or two basic requirements must be known. Neatness and accuracy, especially in the production of a solution to a geometrical problem, are essential.

A good quality drawing paper should be used and this should be secured to a drawing board with clips, and not drawing pins. Try to avoid the use of an eraser, but if it is found necessary, use the plastic type rather than one of the India rubber variety. Select good quality pencils, keep their points well sharpened, preferably with a chisel edge. Keep this edge in a good condition with the use of a small block of wood on which has been glued some very fine glasspaper. Use a medium-hard pencil for drawings and a soft pencil for lettering. Remember, bad lettering can spoil an otherwise well-turned-out drawing, so extra care is required for this. Purchase good quality drawing instruments - cheap ones are never good enough and don't last very long, anyway. Try to keep your instruments in good condition. Set squares should be washed with soap and water regularly so that they do not make drawings grubby. Always draw construction lines thinly and object lines much bolder. Dimension lines should be continuous with the dimension printed above, centrally, if possible.

When producing ink drawings, make the drawing first of all with a pencil on drawing paper, then make a tracing, using good-quality tracing paper and good quality Indian ink. Mistakes made on ink drawings can be removed with the corner of a sharp razor blade, although erasers can be purchased which are made for this purpose. Modern drawing pens should be treated carefully and can be used for long periods before they require cleaning. If, however, they are to be out of use for any length of time they should be cleaned thoroughly with a liquid supplied for that purpose. The basic drawing instruments required are as follows:

A Scale Rule (either metric or imperial, depending on specific requirements). If an imperial scale rule is purchased it should have scales from 3 inches to 1 foot down to $\frac{1}{8}$ inch to 1 foot, and should be 12 inches in length, although smaller ones to fit the pocket are available. A metric scale rule should be $300 \mathrm{~mm}$ in length preferably but smaller ones are available, and should have scales of $1: 1$ up to $1: 2500$.

Set Squares Purchase reasonably large ones (small ones are inadequate for most drawings). A $45^{\circ}$ square and a $30^{\circ} / 60^{\circ}$ square are necessary (or an adjustable square giving a wide range of angles may be used).

Compasses Never buy these from department stores as they are usually of poor quality. Go to a reputable drawing office supplier, select one which has been made by a wellknown manufacturer and pay a reasonably high price for it. In this way you will obtain an instrument that will give many years of good service.

Dividers The notes above for compasses apply for this instrument (it is well to note that good quality compasses can easily be made into dividers by the interchange of the pencil point for a steel point).

Protractor This is used usually for marking off any angle from $0^{\circ}$ up to $180^{\circ}$, but $360^{\circ}$ protractors can also be purchased. 